\title{
CLASSIFICATION OF MULTIVARIATE SAMPLES USING PETUNIN ELLIPSES
}

\author{
D. A. Klyushin, Ya. V. Shtyk \\ Faculty of Computer Science and Cybernetics, Taras Shevchenko Kiev National University, \\ Kiev, Ukraine, E-mail: dokmed5@gmail.com
}

\section{КЛАСИФІКАЦІЯ БАГАТОВИМІРНИХ ВИБІРОК ЗА ДОПОМОГОЮ ЕЛІПСІВ ПЕТУНІНА}

Д. А. Клюшин, Я. В. Штик

Факультет комп'ютерних наук та кібернетики, Київський національний університет імені Тараса Шевченка, Київ, Україна, E-mail: dokmed5@gmail.com

ABSTRACT. The method of classification multivariate samples using Petunin ellipses is investigated in the paper. Several different types of samples were generated for testing. Based on the calculated accuracy of the criteria advantages and disadvantages of each of the linear and quadratic criteria and the specifics of the method as a whole were discovered. It has been found that both linear and quadratic criteria give high accuracy for samples with small variance. As the variance increases, the accuracy of the linear criterion remains high, the accuracy of the quadratic criterion decreases. Both criteria are resistant to sample noise.

Keywords: Petunin Ellipse, Petunin Statistics, Multivariate Sample, Linear Discriminant, Quadratic Discriminant, Classification.

АнотАція. В статті досліджується метод класифікації багатовимірних вибірок за допомогою еліпсів Петуніна. Для тестування було створено вибірки, які мають розподіли різних типів. На основі розрахованої точності запропонованих критеріїв класифікації були виявлені переваги та недоліки кожного з критеріїв та специфіка методу в цілому. Було встановлено, що як лінійні, так і квадратичні критерії дають високу точність для вибірок з невеликою дисперсією. Зі збільшенням дисперсії точність лінійного критерію залишається високою, точність квадратичного критерію зменшується. Обидва критерії стійкі до шуму. Цей важливий факт робить їх корисними у практичному застосуванні. Зокрема, метод виявив високу ефективність при діагностиці раку молочної залози навіть для малих вибірок.

Ключов словА: еліпс Петуніна, статистика Петуніна, багатовимірна вибірка, лінійний дискримінант, квадратичний дискримінант, класифікація. 


\section{INTRODUCTION}

Analyzing data, researchers often face the problem of small amount of available data. With the small amount of data available, achieving high accuracy is an interesting and challenging task. In particular, it is interesting to consider statistical nonparametric methods of classification that are accurate even for small samples (starting from the sample size 40).

To solve this task in the context of breast cancer diagnosis Petunin et al. $[1,2]$ developed methods of linear and quadratic multivariate analysis using projections of data onto the plane. Thus, they reduced the problem of the analysis of $n$-dimensional data to the problem of the analysis of 2-dimensional data. This method is based on the concept of the Petunin statistics [3], which is a measure of samples' homogeneity and plays a role of coordinate at the plane. In the turn, the Petunin statistics uses the MP-model and Hill' assumption $A_{(n)}[4,5,6,7]$.

The accuracy of the method, obtained in [2] is high, but the amount of test data was limited and small, and the properties of data distributions were not known. Thus, the purpose of the paper is to determine how accurate this method is at data artificially generated with special properties and what are its advantages and disadvantages. The novelty of the paper is that the linear and quadratic methods proposed in $[1,2]$ are investigated on the small sample set having different statistical properties for the first time.

\section{Petunin Ellipse}

Let $S$ be a set of equally distributed random variables with an unknown absolutely continuous distribution function $F$. Let $s_{1}, s_{2}, \ldots, s_{n}$ be sampled values from $S$. Sorting sampled values in ascending order we get a variation series $s_{(1)}, s_{(2)}, \ldots, s_{(n)}$. Its components called ordinal statistics.

Theorem 1 (Hill's assumption $\left.A_{(n)}[7]\right)$. If $F$ is an absolutely continuous distribution and $s_{(n+1)}$ is independently sampled from $S$, then

$$
\begin{gathered}
P\left\{s_{(n+1)} \in\left(s_{(i)}, s_{(j)}\right)\right\}=\frac{j-i}{n+1} \\
\text { for } i=\overline{1 \ldots n-1}, j=\overline{2 \ldots n}, i<j .
\end{gathered}
$$

As it will be shown, to analyze the multivariate data using investigated algorithm, it is necessary to construct the Petunin ellipses in the $R^{2}$ space. The Petunin ellipse of the set $S$ is the ellipse with the confidence area that includes $n$ random points of set $S$ with the probability $\frac{n-1}{n+1}$. Figure 1 illustrates an example of the Petunin ellipse.

Let us give a description of construction algorithm. The initial data for the algorithm for the construction of a Petunin ellipse is a set of two-dimensional points $T_{n}=\left\{\left(a_{1}, b_{1}\right), \ldots,\left(a_{n}, b_{n}\right)\right\}$. First, we construct the convex hull of the points $T_{n}$. Then we find two points $\left(a_{i}, b_{i}\right)$ and $\left(a_{j}, b_{j}\right)$ that lying on the diameter of the convex hull. Draw the line $M$ through the points $\left(a_{i}, b_{i}\right)$ and $\left(a_{j}, b_{j}\right)$. Find the farthest vertices $\left(a_{k}, b_{k}\right)$ and $\left(a_{l}, b_{l}\right)$ of the convex hull from the line $M$. Draw through the points lines $M_{1}$ and $M_{2}$ parallel to the line $M$. It is 


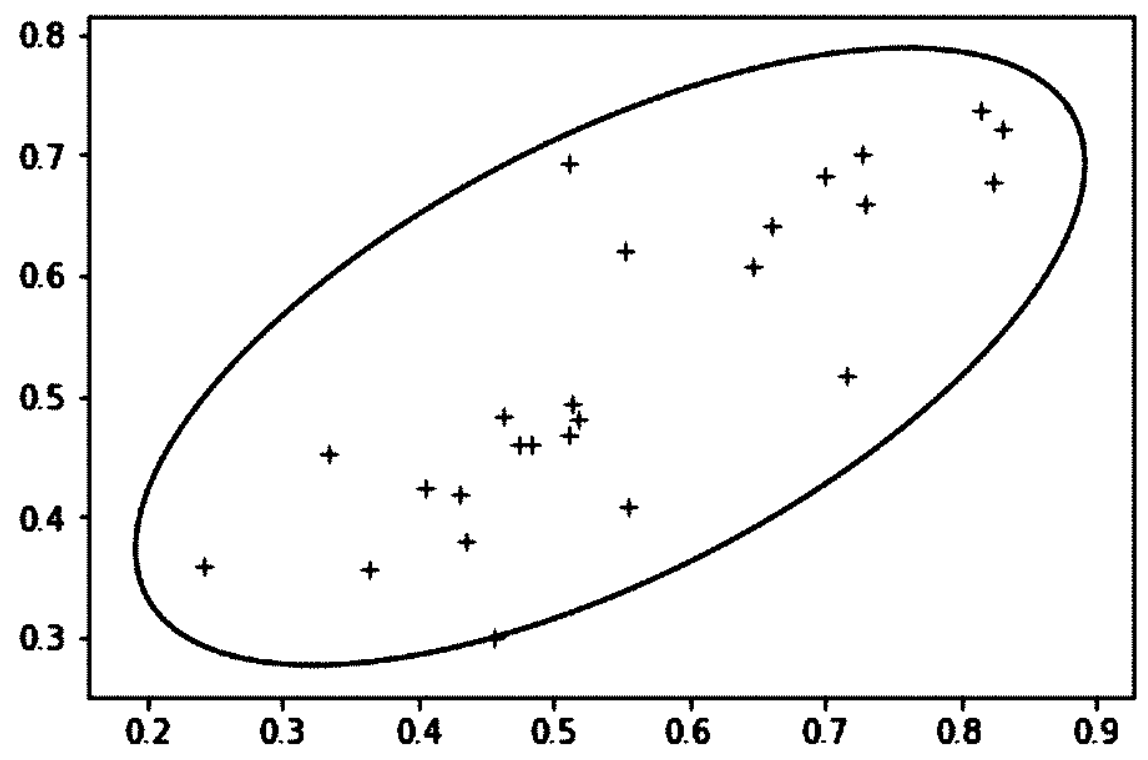

Figure 1. Petunin ellipse.

important to note that the points $\left(a_{k}, b_{k}\right)$ and $\left(a_{l}, b_{l}\right)$ must be on opposite sides of the line $M$. If all points of the convex hull are on one side of line $M$, then the line $M$ coincides with line $M_{2}$. Draw through the points $\left(a_{i}, b_{i}\right)$ and $\left(a_{j}, b_{j}\right)$ two lines $M_{3}$ and $M_{4}$ perpendicular to the line $M$. The intersection of the lines $M_{1}, M_{2}, M_{3}$ and $M_{4}$ form a rectangle whose sides have lengths $k$ and $m$.

Without loss of generality, let $k \leq m$. Let's rotate and move the coordinate system so that the lower left corner of the rectangle is located at the beginning of the new coordinate system. The points $\left(a_{1}, b_{1}\right), \ldots,\left(a_{n}, b_{n}\right)$ will turn into points $\left(a_{1}^{\prime}, b_{1}^{\prime}\right), \ldots,\left(a_{n}^{\prime}, b_{n}^{\prime}\right)$. Than we perform the system compression by multiplying the abscissas of the obtained points by $\mu=\frac{k}{m}$. Obtained points $\left(\mu a_{1}, b_{1}\right), \ldots,\left(\mu a_{n}, b_{n}\right)$ will lie in square $K$. Let $\left(a_{0}, b_{0}\right)$ be a center of the square. Find the distances $d_{1}, d_{2}, \ldots, d_{n}$ from the obtained points to the center.

Now we construct a circle centered at the point $\left(a_{0}, b_{0}\right)$ and radius $R=$ $\max \left(d_{1}, d_{2}, \ldots, d_{n}\right)$. All points $\left(a_{1}^{\prime}, b_{1}^{\prime}\right), \ldots,\left(a_{n}^{\prime}, b_{n}^{\prime}\right)$ lie inside of obtained circle. Stretch the circle along the abscissa with coefficient $\frac{1}{\mu}$. Then we apply the inverse transforms of transfer and rotation and obtain an ellipse in the initial coordinate system. The results is the Petunin ellipse. 


\section{Petunin Statistics}

The Petunin statistics is a measure that estimates the probability that two samples were generated from the same distribution. In other words, this is a measure of the heterogeneity of samples. Let us have two samples $u=$ $\left(u_{1}, u_{2}, \ldots, u_{n}\right)$ and $v=\left(v_{1}, v_{2}, \ldots, v_{n}\right)$ taken from two general sets $S_{1}$ and $S_{2}$ with unknown distribution functions $F_{S_{1}}$ and $F_{S_{2}}$ respectively. We want to find the probability with which we can argue that $F_{S_{1}}=F_{S_{2}}$.

Arrange the elements of each of the samples in ascending order. We obtain variation series $u=\left(u_{(1)}, u_{(2)}, \ldots, u_{\left(n_{1}\right)}\right)$ and $v=\left(v_{(1)}, v_{(2)}, \ldots, v_{\left(n_{2}\right)}\right)$. Let event $I_{i j}$ consist in the fact that $v_{k}$ belong to the interval $\left(u_{(i)}, u_{(j)}\right)$. According to the Hill's assumption: $p\left(I_{i j}\right)=\frac{j-i}{n+1}=p_{i j}$. We can find the frequency $f_{i j}$ of event $I_{i j}$ on the given sample $v=\left(v_{1}, v_{2}, \ldots, v_{n}\right)$ and find confidence intervals for a given probability $p_{i j}$.

The formulas for the boundaries of confidence intervals are:

$$
p_{i j}^{1,2}=\frac{f_{i j} n_{2}+b^{2} / 2 \mp \sqrt{f_{i j}\left(1-f_{i j}\right) n_{2}+b^{2} / 4}}{n_{2}+b^{2}}
$$

In this case, we assume that $n_{2}$ is small, so according to the $3 \sigma$-rule we assign $b=3$. In general case, $b$ must satisfy the condition $\Phi(b)=1-\gamma / 2$, where $\Phi$ is the Gaussian distribution function and $\gamma$ is a given significance level. The number of possible confidence intervals $D_{i j}=\left(p_{i j}^{1}, p_{i j}^{2}\right)$ is equal to $N=\frac{n_{1}\left(n_{1}-1\right)}{2}$. Let $D$ be the number of intervals for which the inclusion $p_{i j} \in\left(p_{i j}^{1}, p_{i j}^{2}\right)$ is true. Find the relative frequency $f=\frac{D}{N}$. The relative frequency $f$ is a measure of homogeneity of the two samples that called $p$-statistics or Petunin statistics.

\section{Homogeneity Measure of a Sample and a Set of Samples in the UNIVARIATE CASE}

Let $u=\left(u_{1}, u_{2}, \ldots, u_{m}\right)$ be a sample from the general set $S_{1}$ with distribution $F_{S_{1}}$. Let $V=\left(v_{1}, v_{2}, \ldots, v_{n}\right)$ where $v_{1}=\left(v_{11}, v_{12}, \ldots, v_{1 n}\right), v_{2}=$ $\left(v_{21}, v_{22}, \ldots, v_{2 n}\right), \ldots, v_{m}=\left(v_{m 1}, v_{m 2}, \ldots, v_{m n}\right)$, be a set which elements is a sample from general set $S_{2}$ with distribution $F_{S_{2}}$. In the studied method, it was proposed to determine the measure of homogeneity of $u$ and $V$ by averaging the Petunin statistics.

First, find the value of Petunin statistics $p\left(v_{i}, u\right)$ for $i=\overline{1, \ldots, n}$. We average the obtained values and get a measure of proximity homogeneity $p$ of the sample and the set of samples:

$$
p=\frac{1}{n} \sum_{i=1}^{n} p\left(v_{i}, u\right) .
$$

Let us try different approach that can be used based on the combining samples $v_{1}=\left(v_{11}, v_{12}, \ldots, v_{1 n}\right), v_{2}=\left(v_{21}, v_{22}, \ldots, v_{2 n}\right), \ldots, v_{m}=\left(v_{m 1}, v_{m 2}, \ldots\right.$, $\left.v_{m n}\right)$ into one sample. So after combining we obtain sample $N=\left(v_{21}, v_{22}, \ldots\right.$, $\left.v_{2 n}, v_{21}, v_{22}, \ldots, v_{2 n}, \ldots, v_{m 1}, v_{m 2}, \ldots, v_{m n}\right)$. We use $N$ to find a measure of homogeneity $p$ between the sample and the set of samples:

$$
p=p(N, u) \text {. }
$$




\section{Homogeneity Measures of a Sample and a Set of Samples in the Multidimensional Case}

Petunin et al. [1, 2] proposed and described a variant of feature-less discriminant analysis, based on tha Petunin ellipses and Petunin statistics. Let us consider groups of objects $V_{1}=\left(a_{1}, a_{2}, \ldots, a_{n}\right)$ and $V_{2}=\left(b_{1}, b_{2}, \ldots, b_{m}\right)$ from classes $A$ and $B$ respectively. Each object is represented by a matrix consisting of rows containing features. For example, in $[1,2]$ objects are patients, and a matrix corresponds to a patient consists of rows containing some features of cell nuclei (nuclear area, integral density etc.). Each matrix has a certain number of rows (from 10 to 30). The columns of such matrices form samples from some distributions (from 10 to 30 real numbers). The main idea is to compare the samples pairwise reducing the multivariate case to a sequence of two-dimensional cases where axes are heterogeneity measures between samples and points are the pairs of the heterogeneous measures computed for each object.

Since the amount of data is small at the $k$ th stage of the test we carry out the one-leave-out cross-validation excluding the $k$ th sample $P$ from the group $V_{1}$ and getting the group $V_{1}^{(k)}=\left(a_{1}, a_{2}, \ldots, a_{k-1}, a_{k+1}, \ldots, a_{n}\right)$. Let

$$
\begin{aligned}
Y_{M_{1}}^{(k)} & =\left(y_{1 k}^{(1)}, y_{2 k}^{(1)}, \ldots, y_{K}^{(1)}\right) \\
Y_{M_{2}}^{(k)} & =\left(y_{1 k}^{(2)}, y_{2 k}^{(2)}, \ldots, y_{K}^{(2)}\right) \\
\ldots & \\
Y_{M_{j_{k}}}^{(k)} & =\left(y_{1 k}^{\left(j_{k}\right)}, y_{2 k}^{\left(j_{k}\right)}, \ldots, y_{K}^{\left(j_{k}\right)}\right)
\end{aligned}
$$

be the object $a_{k}$, where $Y_{i}, i=\overline{1, \ldots, j_{k}}$ is sub-objects of object $a_{k}$ and $j_{k}$ is a number of sub-objects in $a_{k}, k=\overline{1, \ldots, n}$. In this case the number of features is $K$.

After exclusion we form a training sample for each feature $x_{i}, i=\overline{1, \ldots, K}$. For feature $x_{1}$ the training sample has the form

$$
\begin{gathered}
Y_{1}^{(1)}=\left(y_{11}^{(1)}, y_{11}^{(2)}, \ldots, y_{11}^{\left(j_{1}\right)}\right) \\
Y_{2}^{(1)}=\left(y_{12}^{(1)}, y_{12}^{(2)}, \ldots, y_{12}^{\left(j_{2}\right)}\right) \\
\ldots \\
Y_{n}^{(1)}=\left(y_{1 n}^{(1)}, y_{1 n}^{(2)}, \ldots, y_{1 n}^{\left(j_{n}\right)}\right) .
\end{gathered}
$$

Similar samples are obtained for all features. We apply the method described above for finding the heterogeneity measure between samples for each feature. For example, for first feature $y_{1}$ the sample is the features $y_{1}$ of $k$ th object $\left(y_{1 k}^{(1)}, y_{1 k}^{(2)}, \ldots, y_{1 k}^{\left(j_{k}\right)}\right)$ and the set of samples is a training sample for the feature $y_{1}$. As a result, we get a heterogeneity measure $p_{k}^{(1)}$. In the same way we find heterogeneity measure of the object $a_{k}$ and training sample for each feature $y_{i}, i=\overline{1, \ldots, K}$. Replacing the object of the group $V_{1}$ with the object of the group $V_{2}$ we get heterogeneity measures $\left(\overline{p_{k}^{(1)}}, \overline{p_{k}^{(2)}}, \ldots, \overline{p_{k}^{(K)}}\right)$ for $k$ th object of 
group $V_{2}$. If we replace the group $V_{1}$ by $V_{2}$ and carry out similar calculations, we obtain the heterogeneity measures $\left(z_{i}^{(1)}, z_{i}^{(2)}, \ldots, z_{i}^{(K)}\right), i=\overline{1 \ldots n}$ and $\left.\overline{\left(z_{j}^{(1)}\right.}, \overline{z_{j}^{(2)}}, \ldots, \overline{z_{j}^{(K)}}\right), j=\overline{1 \ldots m}$.

For the ellipses construction we combine the averaged Petunin statistics into pairs $\left(p_{k}^{(i)}, p_{k}^{(j)}\right),\left(\overline{p_{t}^{(i)}}, \overline{p_{t}^{(j)}}\right), k=\overline{1, \ldots, n}, t=\overline{1, \ldots, m}, i, j=\overline{1, \ldots, K}$. Similarly we get the pairs $\left.\left(z_{k}^{(i)}, z_{k}^{(j)}\right), \overline{\left(z_{t}^{(i)}\right.}, \overline{z_{t}^{(j)}}\right), k=\overline{1, \ldots, n}, t=\overline{1, \ldots, m}, i, j=\overline{1, \ldots, K}$. So we obtain points in space $R^{2}$. Then by point $\left(p_{k}^{(i)}, p_{k}^{(j)}\right), k=\overline{1 \ldots n}, i, j=$ $\overline{1 \ldots K}$ we construct Petunin ellipses $E_{i j}$. Then we construct Petunin ellipses

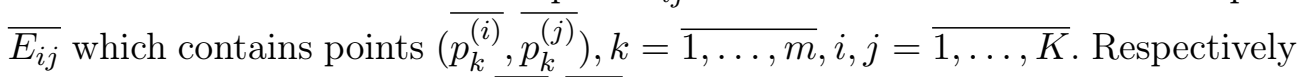
using points $\left(z_{k}^{(i)}, z_{k}^{(j)}\right)$ and $\left(\overline{z_{k}^{(i)}}, \overline{z_{k}^{(j)}}\right) k=\overline{1, \ldots, n}, i, j=\overline{1, \ldots, K}$ we obtain Petunin ellipses $D_{t s}$ and $\overline{D_{t s}}$.

The linear discriminant functions is using to separate two sets in space. We construct the linear discriminant functions that separate the set $S_{i j}^{p}=$ $\left\{\left(p_{t}^{(i)}, p_{t}^{(j)}\right), t=\overline{1, \ldots, n}\right\}$ from the set $\overline{S_{i j}^{p}}=\left\{\left(\overline{p_{k}^{(i)}}, \overline{p_{k}^{(j)}}\right), k=\overline{1, \ldots, m}\right\}$ and set $S_{i j}^{z}=\left\{\left(z_{t}^{(i)}, z_{t}^{(j)}\right), t=\overline{1, \ldots, n}\right\}$ from the set $\overline{S_{i j}^{z}}=\left\{\left(\overline{z_{k}^{(i)}}, \overline{z_{k}^{(j)}}\right), k=\overline{1, \ldots, m}\right\}$. We construct the linear discriminants using the Roccio method so that the line $l_{i j}^{p}=\left\{(x, y): f_{i j}(x, y)=0\right\}$ is perpendicular to line on which the centers of the sets $S_{t s}^{p}$ and $\overline{S_{t s}^{p}}$ lie and is located at the same distance from the centers. Moreover, the center of set $S_{t s}^{p}$ is in the half-plane $\eta_{i j}$ and the center of set $\overline{S_{t s}^{p}}$ is in the half-plane $\mu_{i j}$. The function $f_{i j}^{*}$ is constructed in the same way. So if we have $K$ features we obtained $K(K-1)$ pairs of half-spaces $\left(\eta_{i j}, \mu_{i j}\right),\left(\eta_{i j}^{*}, \mu_{i j}^{*}\right)$.

Let $R$ be an object that needs to be classified. Using the algorithm from Section 2 we find averaged Petunin statistics $p$ and $d$. We will analyse obtained heterogeneity measures using Petunin ellipses. Introduce the following events: $J_{1}=\left\{\left(p_{R}^{(i)}, p_{R}^{(j)}\right) \in E_{i j}\right\}, J_{2}=\left\{\left(p_{R}^{(i)}, p_{R}^{(j)}\right) \in \overline{E_{t s}}\right\}, J_{3}=\left\{\left(p_{R}^{(i)}, p_{R}^{(j)}\right) \in E_{t s}-\right.$ $\left.\overline{E_{t s}}\right\}, J_{4}=\left\{\left(p_{R}^{(i)}, p_{R}^{(j)}\right) \in \overline{E_{t s}}-E_{t} s\right\}, J_{1}^{*}=\left\{\left(z_{R}^{(i)}, z_{R}^{(j)}\right) \in D_{i j}\right\}, J_{2}^{*}=\left\{\left(z_{R}^{(i)}, z_{R}^{(j)}\right) \in\right.$ $\left.\overline{D_{i j}}\right\}, J_{3}^{*}=\left\{\left(z_{R}^{(i)}, z_{R}^{(j)}\right) \in D_{t s}-\overline{D_{t s}}\right\}, J_{4}^{*}=\left\{\left(z_{R}^{(i)}, z_{R}^{(j)}\right) \in \overline{D_{t s}}-D_{t s}\right\}$, $K_{1}=\left\{\left(p_{R}^{(i)}, p_{R}^{(j)}\right) \in \alpha_{i j}\right\}, K_{2}=\left\{\left(p_{R}^{(i)}, p_{R}^{(j)}\right) \in \beta_{i j}\right\}, K_{1}^{*}=\left\{\left(z_{R}^{(i)}, z_{R}^{(j)}\right) \in \alpha_{i j}^{*}\right\}, K_{2}=$ $\left\{\left(z_{R}^{(i)}, z_{R}^{(j)}\right) \in \beta_{i j}\right\}, i<j H_{1}=J_{3} \bigcup J_{4}^{*}, H_{2}=J_{4} \bigcup J_{3}^{*}, H_{3}=J_{1} \bigcup J_{2}^{*}, H_{4}=$ $J_{2} \bigcup J_{1}^{*}, H_{5}=K_{1} \bigcup K_{2}^{*}, H_{6}=K_{2} \bigcup K_{1}^{*}$.

Let us introduce a relative frequencies $h_{i}=h\left(H_{i}\right), i=\overline{1, \ldots, 6}$ of each of the events $H_{i}, i=\overline{1, \ldots, 6}$ in $N$ tests, which we can run changing values of $i$ and $j$. The relative frequency $h_{1}$ corresponds to class $A$ excluding overlapping with class $B, h_{3}$ corresponds to class $A$ including overlapping with class $B, h_{2}$ and $h_{4}$ as relative frequency of class $B$ excluding overlapping with class $A$ and relative frequency of class $B$ including overlapping with class $B$ respectively. The frequencies $h_{5}$ and $h_{6}$ corresponds to the half-planes containing objects of class $A$ and class $B$ respectively. 


\section{Classification of Multivariate Samples}

In this section, we test the investigated algorithm. To check the correctness of the algorithm, we will construct an experiment with linearly separable samples. We will generate samples using the Gaussian normal distribution.

We have two classes $A$ and $B$. Each class object is a matrix. Each matrix contains from 10 to 30 rows. Columns of the matrixes are samples containing features. Each feature has Gaussian distribution with variance equal to 1 and its own mean value. Let the number of features be $K$. Objects features of class $A$ have average values from 0 to $K$. That is, the first feature is generated from the Gaussian distribution $N(0,1)$, the second one is generated from distribution $N(1,1)$, the fifteenth is generated from the distribution $N(14,1)$. Features of class $B$ have Gaussian distributions with averages from 15 to 30 and a variance equal to 1 . That is, the first feature of class $B$ is generated from the distribution $N(15,1)$, the second one is generated from $N(16,1)$, the fifteenth is generated from $N(29,1)$.

We generate a sample that consist of 25 objects of each class. Then we perform one-leave-out cross-validation. In fact, at each iteration of the test we divide initial sample into a test sample, which consists of one object, and a training sample that includes all others objects. That is, the result of each iteration of the test is the conclusion about the belonging of the tested object to each of the two classes $A$ and $B$. Conclusion is presented in the form of 6 statistics $h_{i}, i=\overline{1, \ldots, 6}$, which described below. As a result of the algorithm, we obtain a set of relative frequencies of each object of initial sample. Analyzing the set we can draw conclusion about correctness of the algorithm.

In $[1,2]$ the quadratic and linear tests for determining the class of a tested object were proposed. These tests were formulated as follows.

Quadratic test: $h_{3}>h_{4} \Rightarrow A, h_{3} \leq h_{4} \Rightarrow B$.

Linear test: $h_{5}>h_{6} \Rightarrow A, h_{5} \leq h_{6} \Rightarrow B$

Stable test: $h_{3}>h_{4} \wedge h_{3}>h_{2} \Rightarrow A, h_{3} \leq h_{4} \wedge h_{1} \leq h_{2} \Rightarrow B$

The effect of the stable dominance of the group $A$ is the case when $h_{3}>h_{4}$ and $h_{5}>h_{6}$. Similarly the effect of the stable dominance of the group $B$ is the case when $h_{3} \leq h_{4}$ and $h_{5} \leq h_{6}$. Analyzing $h$-statistics we obtain the accuracy of the described criteria. The accuracy of each criteria in percents is equal to 100. It can be seen that on a linearly separable sample the method has absolute accuracy. Obtained result allows us to argue that the algorithm is correct and it is possible to use it in practice. Now it is important to check the accuracy of the method on more complex samples. As we can see the accuracy of the criteria has decreased. At the same it is high level of accuracy. Obtained results suggest that for samples with a small variance we can successfully use studied method.

Analyzing $h$-statistics obtained for each of the cases, it was noticed that the $h_{1}$ is give an information of belonging to class $A$ at most cases. The similar relations was noticed between statistics $h_{2}$ and class $B$. In this connection, let us introduce a modified test that is based only on $h_{1}$ and $h_{2}$ statistics. We formulate the criteria as follows: $h_{1}>h_{2} \Rightarrow A, h_{1} \leq h_{2} \Rightarrow B$. The accuracy of the introduced criterion for each of the cases is shown in Table 1. 
We complicate the classification task by increasing the variance of the Gaussian distribution. Let the variance be 2 for all the distributions that are used. Means of distributions are the same as in the previous section and are equal $(0,2, \ldots, 28)$ and $(1,3, \ldots, 29)$ for class $A$ and $B$ respectively. It should be noticed that the intervals between the averages of the same features of different classes are equal to 1 , and the variance is two times greater than this value.

It is important to understand that generated data is difficult to test. In fact it is not distinguished by human. It can be seen that the linear criterion has better accuracy and can be successfully used in practice. Quadratic criterion can be successfully used for data with small variance.

In most practical tasks, we work with data that are inaccurate, or noised. Analyzing it we understand that the actual data may vary. Therefore it is important to check how much noise affects accuracy. For this purpose we will generate a sample with the means $(0,2, \ldots, 28)$ and $(1,3, \ldots, 29)$ for classes $A$ and $B$ respectively and variance equal to 1 . We add to obtained sample the noise generated from the Gaussian distribution $N(0,0.2)$.

Analyzing accuracy of the tests shown in the Table 1 we may argue that the stable test is resistant to noise. Moreover it is seen than both linear and quadratic criteria give good accuracy in this case. For original linearly separated samples the linear, quadratic, stable and modified tests demonstrate the ideal accuracy. For samples with small variance the accuracy of the quadratic test decreases while the accuracy of the linear, stable, and modified tests are quite high. For samples with large variance the accuracy of the quadratic and stable tests decreases. For samples with the Gaussian noise the stable test is the most accurate.

\begin{tabular}{|c|c|c|c|c|c|c|c|c|c|c|c|c|}
\hline \multirow{2}{*}{ Test } & \multicolumn{4}{|c|}{ Original } & \multicolumn{3}{c|}{ Small variance } & \multicolumn{3}{c|}{ Large variance } & \multicolumn{3}{|c|}{ Gaussian noise } \\
\cline { 2 - 13 } & $\mathrm{A}$ & $\mathrm{B}$ & $\mathrm{AB}$ & $\mathrm{A}$ & $\mathrm{B}$ & $\mathrm{AB}$ & $\mathrm{A}$ & $\mathrm{B}$ & $\mathrm{AB}$ & $\mathrm{A}$ & $\mathrm{B}$ & $\mathrm{AB}$ \\
\hline Linear & 100 & 100 & 100 & 100 & 88 & 94 & 88 & 92 & 90 & 88 & 96 & 92 \\
Quadratic & 100 & 100 & 100 & 100 & 96 & 98 & 50 & 80 & 50 & 64 & 88 & 76 \\
Stable & 100 & 100 & 100 & 100 & 88 & 94 & 68 & 72 & 70 & 72 & 88 & 80 \\
Modified & 100 & 100 & 100 & 100 & 100 & 100 & 80 & 84 & 82 & 88 & 100 & 94 \\
\hline
\end{tabular}

Table 1. Accuracy of tests with different variances and noise.

\section{Conclusions}

It has been found that both linear and quadratic criteria give high accuracy for samples with small variance. As the variance increases, the accuracy of the linear criterion remains high, the accuracy of the quadratic criterion decreases. Both criteria are resistant to sample noise. This important fact makes them useful in practical applications. The future scope of the method is connected with the applications in different fields and investigations of more strong variants of relative frequencies comparisons based on confidence intervals. The question of the accuracy of the method when using confidence intervals for comparing binomial proportions in the Matveychuk-Petunin scheme remains open. 


\title{
REFERENCES
}

1. Petunin Yu. I., Klyushin D. A., Ganina K. P., Boroday N.V., Andrushkiw R.I. Computer-aided diagnosis of breast cancer. Part 1. Mathematical aspects. Istatistik. 1999. Vol. 2. P. 71-86.

2. Petunin Yu. I., Klyushin D. A., Ganina K. P., Boroday N.V., Andrushkiw R. I. Computer-aided diagnosis of breast cancer. Part 2. Tests and experiments Istatistik. 1999. Vol. 2. P. 87-105.

3. Klyushin D.A., Petunin Yu. A Nonparametric Test for the Equivalence of Populations Based on a Measure of Proximity of Samples Ukrainian Math. J., 2003, Vol. 55. No. 2. P. 181-198.

4. Matveichuk S. A., Petunin Yu. I. Generalization of Bernoulli schemes that arise in order statistics, I. Ukrainian Math. J.. 1990. Vol. 42. No. 4. P. 459-466.

5. Matveichuk S.A., Petunin Yu.I. Generalization of Bernoulli schemes that arise in order statistics, II. Ukrainian Math. J.. 1991. Vol. 43. No. 6. P. 728-734.

6. Johnson N., Kotz S. Some generalizations of Bernoulli and Polya-Eggenberger contagion models. Statist. Paper. 1991. Vol. 32. P. 1-17.

7. Hill B.M. Posterior distribution of percentiles: Bayes' theorem for sampling from a population. J Am Stat Assoc. 1968. Vol. 63. P. 677-691.

8. Lyashko S.I., Klyushin D.A., Alexeyenko V.V. Multivariate ordering using elliptical peeling. Cybernetics and System Analysis. 2013. Vol. 49, P. 511-516.

Received: 4.05.2020 / Accepted: 21.05.2020

\section{КЛАССИФИКАЦИЯ МНОГОМЕРНЫХ ВЫБОРОК С ПОМОЩЬЮ ЕЛИПСОВ ПЕТУНИНА}

\author{
Д. А. Клюшин, Я. В. Штык
}

Факультет компьютерных наук и кибернетики, Киевский национальный университет имени Тараса Шевченко, Киев, Украина, E-mail: dokmed5@gmail.com

АннотАция. В статье исследуется метод классификации многомерных выборок с помощью эллипсов Петунина. Для тестирования были сгенерированы несколько выборок с разными распределениями. На основании рассчитанной точности критериев были выявлены преимущества и недостатки каждого из линейных и квадратичных критериев и специфика метода в целом. Было обнаружено, что как линейные, так и квадратичные критерии дают высокую точность для выборок с малой дисперсией. С увеличением дисперсии точность линейного критерия остается высокой, точность квадратичного критерия уменьшается. Оба критерия устойчивы к шуму.

КлючевыЕ СЛОвА: эллипс Петунина, статистика Петунина, многомерная выборка, линейный дискриминант, квадратичный дискриминант, классификация. 